\title{
A CRÔNICA E A CIDADE DE CAMPOS RIBEIRO
}

Alcione do Nascimento CAREPA

Paulo NUNES

\begin{abstract}
RESUMO
A crônica é uma modalidade literária que permite ao leitor identificar marcas de fatos históricos diante da história narrada. É neste gênero que o autor consegue mostrar fatos reais usando a escrita literária. O que permite que essa narrativa não envelheça. A crônica Moral e Cívica, de De Campos Ribeiro tem essas características que a transformam em um texto documental guardando por muitos anos e que retrata a imagem da cidade de Belém desde o início do século XX até meados da década de 65. Este estudo leva em consideração o fato de De Campos Ribeiro ter sido jornalista, participado efetivamente do Modernismo paraense junto com outros intelectuais da mesma época. Homens esses que na maioria moraram na periferia, pretos, pobres e autodidatas. Estes homens idealizaram a Academia do Peixe-Frito, nome dado aos encontros informais desses pensadores, fato que compõe esta análise. Tal estudo tenta explicar o cotidiano vivido por De Campos Ribeiro no texto, o que resultou em uma representação da cidade de Belém por meio do imaginário e do fato pensado por ele e contado em forma de narrativa no livro de autoria de De Campos Ribeiro "Gostosa Belém de Outrora". Obra que demonstra vasta sensibilidade de observação do autor diante da cidade, dos moradores e dos problemas urbanos vivenciados pelos belenenses nas primeiras décadas do século XX.
\end{abstract}

Palavras-chave: De Campos Ribeiro. Academia do Peixe Frito. Literatura. Crônica. Modernismo.

\begin{abstract}
The chronicle is a literary modality that allows the reader to identify marks of historical facts before the story told. It is in this genre that the author is able to show real facts using literary writing. What allows this narrative does not age. The Moral and Civic Chronicle, De Campos Ribeiro has these characteristics that transform it into a documentary text for many years and that portrays the image of the city of Bethlehem since the beginning of the 20th century until the mid-65's. This study takes into account the fact that De Campos Ribeiro having been a journalist, participated effectively in the Modernism of Pará along with other intellectuals of the same time. Men who mostly lived in the periphery, black, poor and self-taught. These men idealized the Academy of Fish-Fried, name given to the encounters of these thinkers, a fact that composes this analysis. Such a study attempts to explain everyday lived by De Campos Ribeiro in the text, which resulted in a representation of the city of Belém by means of the imaginary and the fact thought by him and counted in the form of narrative in the book of authorship of De Campos Ribeiro "Gostosa Belém de Outrora". Work that shows vast sensitivity of the author's observation of the city, the inhabitants and urban problems lived by the Belenenses in the first decades of the twentieth century.
\end{abstract}

Keywords: De Campos Ribeiro. Fried Fish Academy. Literature. Chronic. Modernism.
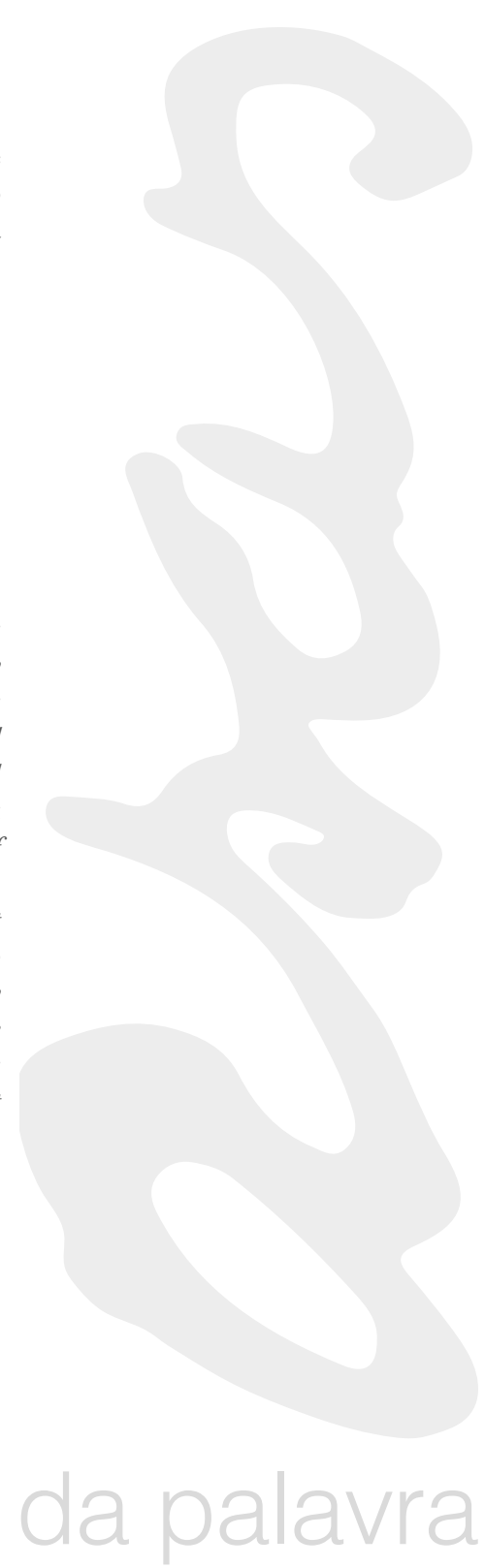

VOL. 15 | N. 1 | JUL. 2018 
De Campos Ribeiro

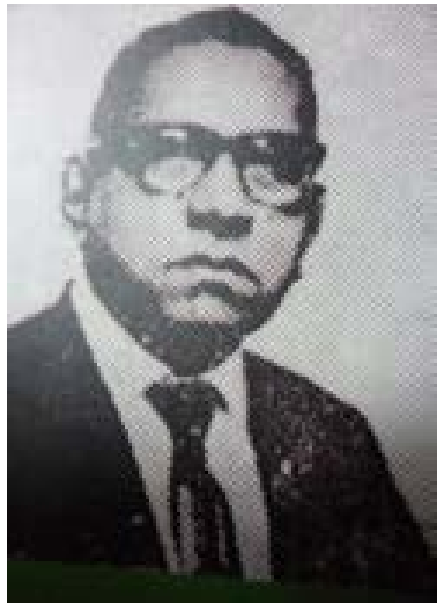

Para entendermos a participação de José Sampaio De Campos Ribeiro como literato, jornalista atuante e preocupado com a cidade de Belém e as pessoas que aqui viviam será preciso discutirmos De Campos Ribeiro como participante efetivo de um grupo de intelectuais que mantinham encontros informais para comer peixe frito, tomar cachaça e debater assuntos dos mais diversos possíveis, o que culminou na fundação da chamada "Academia do Peixe Frito".

Segundo Leal (2014) a Academia do Peixe Frito agregava vários intelectuais participantes deste grupo, entre eles, Bruno de Menezes, poeta precursor do Modernismo paraense. Esses intelectuais e literatos tinham o hábito de se encontrarem na feira do Ver-o-Peso; feira localizada às margens da baía do Guajará, ponto de comércio, de encontros entre belenenses e ribeirinhos, lugar de cheiros, sabores e cores na cidade de Belém (Nunes; Costa 2016).

De Campos Ribeiro como integrante da Academia do Peixe Frito e jornalista atuava nos jornais impressos de Belém, assim como escrevia crônicas que eram publicadas nos jornais e mais tarde em livro. Paralelamente, ele escrevia para a Belém Nova, revista fundada por Bruno de Menezes, principal representante do Modernismo paraense, que circulou de 1923 a 1929. Segundo Leal (2014), a revista tinha como linha editorial a difusão das obras de autores paraenses, propagando, assim, os conceitos modernistas entre nós.

Há fatos que podem servir de referência testemunhal de De Campos Ribeiro em relação às crônicas escritas por ele. Halbwachs (2006) é quem nos fala sobre testemunhos e lembranças coletivas. "Nossas lembranças permanecem coletivas e nos são lembradas por outros, ainda que se tratem de eventos em que somente nós estivemos e objetos que somente nós vimos. Isto acontece porque jamais estamos sós" (HALBWACHS, 2006 p. 30).

A crônica de De Campos Ribeiro aqui analisada, será pensada como uma representação da memória coletiva de um grupo do qual ele fazia parte.

O jornalista De Campos Ribeiro tinha experiência no jornalismo, ele trabalhou durante 50 anos no jornal Estado do Pará, de 1918 a 1968. Maranhense, veio para Belém aos 4 anos de idade, aqui permanecendo até sua morte, em setembro de 1980. Sua atuação, como jornalista, na imprensa da capital paraense, teve início aos 17 anos, passando pelos jornais "A Província do Pará", "Folha do Norte", "Correio do Pará", "O Estado do Pará", onde foi redator e editor, e "O Liberal", local em que sofreu um infarto, em 1968, aposentando-se do ofício de jornalista aos 67 anos (BLOG ARLS DE CAMPOS RIBEIRO 51).

De Campos Ribeiro, por meio de suas crônicas, pensa a capital paraense como uma cidade em crescimento populacional e demonstra nos seus textos a cidade que também tem problemas periféricos e que tem como parte da memória rios e igarapés que ficam á margem da capital paraense. É com esta visão que coincide com a de Certeau (1994), que nos ajuda a pensar quando ele diz que cidade é "a produção de um espaço próprio: a organização racional deve, portanto, recalcar todas as poluições físicas, mentais ou políticas que a comprometeriam”. (CERTEAU, 1994 p. 173) 
Antes de nos aprofundarmos no texto de De Campos, conheçamos um pouco da crônica como modalidade de narrar. A crônica, inicialmente, relacionava os acontecimentos em ordem cronológica. Contava a história de acordo com o tempo, Moisés (1978). Essa observação foi feita na Europa no início da era cristã. De lá para cá, houve a inclusão de traços literários. A história e a ficção se fez mais presente nos textos e assim deu a origem a esse gênero literário que mantem a relação entre a realidade e a memória dos autores.

O jornalismo absorve a crônica já no século XIX com uma concepção moderna e sentido estritamente literário. É quando o estilo integra as páginas dos jornais, tomando para si a função de contar histórias diárias, como ficção, amenizando a veracidade do ocorrido, Moisés (1978).

Com o passar do tempo, a crônica se tornou uma modalidade literária, se dividindo entre as páginas dos jornais e dos livros, texto usado na Europa e depois no Brasil, a crônica também foi chamada de folhetim e começou a ganhar uma característica de narrativa, que Moisés (1978) chama de "Narrativa Histórica". Esse novo formato foi aceito e usado por muitos escritores brasileiros.

É dentro desta perspectiva que a Narrativa será abordada, de acordo com o que Motta (2013) fala a respeito da função da Narratologia que é "relatar eventos de interesse humano enunciados em um suceder temporal encaminhado a um desfecho" (MOTTA, 2013, p. 71). É diante dessa forma de narrar, estabelecendo uma transformação no sentido da história humana que encaminharemos o estudo.

Para Motta (2013) contar uma história com começo, meio e fim faz parte da experiência humana. Considerando a experiência do jornalista De Campos Ribeiro nas redações de jornais paraenses e na escrita das crônicas literárias é que o artigo propõe observar as nuances do autor que, aparentemente, se mostra circular nos dois campos da escrita literária e jornalística na crônica "Moral e Cívica". Assim Motta (2013) discorre a respeito.

A narrativa põe naturalmente os acontecimentos em perspectiva, une pontos, ordena antecedentes e consequentes, relaciona coisas, cria o passado, o presente e o futuro, encaixa significados parciais em sucessões temporais, explicações e significações estáveis. (MOTTA, 2013, p. 71).

É o que se percebe na crônica de De Campos Ribeiro, "Moral e Cívica", do livro "Gostosa Belém de Outrora", em que o autor relaciona a importância da imprensa, do repórter e do fato como destaque no jornal, representado na crônica por uma manifestação popular, em relação à cobrança do patriotismo dos paraenses em relação aos estrangeiros, fato que aconteceu na década de 20. Nesse caso é bom lembrar o que fala o Gonzaga Motta, "ao narrar, alguém está explorando na sua imaginação possíveis desenvolvimentos (reais ou ficcionais) das condutas e comportamentos humanos". (MOTTA, 2013 p. 72), será nessa perspectiva que a crônica "Moral e Cívica", de De Campos Ribeiro, entra nesta discussão.

Essa crônica será observada como uma narrativa que tem o papel de mexer com a imaginação do leitor, envolvendo-o no acontecimento. Desta forma, pensaremos esta crônica, como um gênero "híbrido", na ótica de Moisés (1978), entre o jornalismo e a literatura, utilizando o conceito de "hibridismos" na observação deste texto literário, com a visão de que o jornalista escreve os fatos em tom de verdade e o poeta escreve inspirando-se no cotidiano. É o que se propõe diante da observação deste texto. fato notícia,

"Moral e Cívica" é um texto que tena se aproximar do leitor por meio do

De forma simplificada, notícia é todo fato relevante que desperte interesse público, ensinam os manuais de jornalismo. Fora dos manuais, notícia na verdade é tudo que os jornalistas escolhem oferecer ao público. (RICARDO NOBLAT, 2006, apud. MENDES, 2007, p. 2).

O fato que aparentemente despertou interesse de De Campos Ribeiro foi a 
revolta popular que aconteceu em Belém, mais especificamente no centro da cidade, em que manifestantes, voltaram-se contra estrangeiros que viviam na capital. A manifestação aconteceu por causa da falta de cuidado de um estrangeiro ao descartar a bandeira brasileira no rio.

No texto, o autor discute a ideia da importância da bandeira, ou do que ela representa aos brasileiros, De Campos transforma o fato notícia numa empolgante narrativa, a forte expressividade do texto nos faz pensar que estamos ouvindo mais do que lendo o texto, Motta (2013) pensa sobre estas ideias dos textos, ele diz que: ouvintes de uma narrativa não captam apenas as sequencias dos acontecimentos representados (a trama ou enredo). Captam também aspectos ocultos ou virtuais das personagens e das ações que requerem novos pensamentos de parte de cada um (MOTTA, 2013 p.73).

em outras palavras, a ideia que o autor defendeu pode ter várias significações para quem lê, pode dar a ilusão de relação de continuidade do texto. Que neste caso, pode ser a representação patriótica dos belenenses.

A narrativa fala de um cidadão português, personagem da crônica que joga fora a bandeira nacional brasileira. Diante do texto, o que aparenta é que o estrangeiro deixa uma imagem de que não se importa com o significado da bandeira para os belenenses e que, por esse motivo, os nativos protestam contra os estrangeiros que viviam em Belém. Leiamos parte da crônica:

Tão Séria era a religiosidade veneração à Bandeira que certa noite, aì por 1920, resultou em Belém num quebra-quebra danado. Não houve, em consequência dele, farol "olho de boi" de bonde, nem vibrações de Garapeira, do Vêr-o-Pêso a Nazaré, que ficassem inteiros... (DE CAMPOS, 2005, p. 92, grifo nosso).

O caso começou quando um marinheiro português ao substituir a bandeira envelhecida do mastro por uma nova, não tomou cuidado de no descarte da antiga e a jogou do barco no rio. Essa ação casou indignação aos patriotas, vigilantes de plantão. Revoltados, os manifestantes saíram as ruas do centro da cidade:

Um patriota qualquer viu o "atentado". Sopapeou, logo de saída, o homemzinho, na mesma hora levado aos empurrões, com mais algumas biscas de quebra, já por grossa massa exaltada, para a Central de Polícia. [...] "Vamos à garagem do Remo!" [clube de futebol] E para o Largo da Sé rumou aquêle trôço entusiasmado, dando vivas ao Brasil e "Abaixo os galegos!"(DE CAMPOS, 2005, p. 93)

De Campos Ribeiro, ao narrar o acontecimento, posiciona-se como um “cronista histórico" (CHIQUIM, 2010, p. 39) que segundo o autor, é quando o narrador oral utiliza da memória para recuperar os acontecimentos vividos e transforma essa experiência em um texto narrativo de cunho histórico. A oralidade, diga-se de passagem, é a forma tradicional com que os pretos herdam de seus ancestrais africanos o modo de contar suas histórias. Moral e Cívica não foge à origem literária a que se propõe, mas traz no discurso as citações que lembram a um texto jornalístico. De Campos escreve logo no primeiro parágrafo, o flagrante fotográfico do repórter, a foto que virou destaque no jornal. Além disso, mais adiante, ele destaca o fato dos manifestantes terem lembrado a importância da imprensa e também a repercussão do protesto no dia seguinte.

Flagrante, em alegria inusitada, o repórter flagrou, segundo o bom estilo da semântica jornalístico-policial, no ângulo certo de fotógrafo que se preza, o popular que se descobria, à passagem do Pavilhão Nacional. [...] A turma esbravejante foi à Associação da Imprensa, então no prédio que hoje ocupado pelo Cedro Esporte Clube, perto do Cinema Olímpia. [...] Manhã seguinte, nos jornais o balanço da generalizada desordem que a cidade sofrera.(DE CAMPOS RIBEIRO, 2005, p. 91) 
A partir do texto literário à experiência do autor, destacando a importância do flagrante na ação do jornalista. Tófoli (2008) é lembrado depois dessa citação para mencionarmos a técnica da profissão do jornalista. "O jornalista é entendido como a atividade profissional cuja finalidade é captar e transmitir informações, obedecendo a um conjunto de técnicas, saber e ética" (TÓFOLI, 2008, p. 21).

Evidente que essa definição é a base estrutural e objetiva da função do jornalista e entrou com a finalidade de nos fazer pensar sobre a escolha de De Campos Ribeiro em começar a crônica a partir de um parágrafo que dá ênfase à prática do repórter. Pressupõe-se, seguindo esse pensamento, a inferência no texto literário por meio da experiência vivenciada do autor no mundo da reportagem.

Está, porém, no contexto do jornalista que se tornara escritor, a base do olhar para essa crônica. É bem verdade que, em meados do século XX, a troca de funções entre jornalistas e escritores deixaram rastros nos dois tipos de texto. Sodré (1999) ressalta que essa fase do jornalismo brasileiro foi predominantemente literária.

Do ponto de vista enunciativo, De Campos se inclui na história, usando a primeira pessoa, o que na crônica pode ser feito, mas no texto jornalístico não é recomendável. "Para mim, e na certa para as gentes da "velha guarda", que de relembranças não acordou...” (DE CAMPOS RIBEIRO, 2005, p. 91). É a força da linguagem literária disputando espaço com a linguagem jornalística. Sant'Anna nos lembra, afinal, que "o cronista é um jornalista a quem é permitido falar em primeira pessoa" (SANT'ANNA, 1997, p. 272).

O que parece é que o autor paraense escreve a crônica transpassando, de personalidade o acontecimento noticiado nos jornais, o que deixa claro a aproximação da crônica com o texto jornalístico, talvez caiba lembrar à reflexão de Moisés (1978) que afirma que a crônica é um texto escrito para ser lido no jornal e não para o jornal. Conforme se lê:

A crônica move-se entre ser no e para o jornal, uma vez que se destina, inicial e precipuamente, a ser lida no jornal ou revista. Difere, porém, da matéria substancialmente jornalística naquilo em que, apesar de fazer do cotidiano o seu húmus permanente, não visa à mera informação. (MOISÉS, 1978, p. 247).

O objetivo da crônica é universalizar o fato, torná-lo atemporal, transformá-lo em ficção, o que, necessariamente, não deixa de lado o fato de ter sido um acontecimento frio, trivial e descolorido (Moisés,1978). O texto Moral e Cívica é um exemplo de texto literário que demonstra o factual noticiado na imprensa como inspiração para a literatura. Os dois textos têm estilos diferentes, técnicas de escrita diferentes, o que levamos em consideração aqui é a inspiração:

[...] o conhecimento e o reconhecimento do código linguístico, haja vista que o jornalismo se propõe a processar informações em escala industrial e para consumo imediato e, diferentemente da literatura, deve reduzir as variáveis formais e escapar da limitação das formulas rígidas, (LAGE, apud TOFOLI, 2008, p. 22).

Mesmo usando códigos linguísticos diferentes, o autor segue em frente deixando vestígios de décadas de profissão:

A turma esbravejante foi à Associação da Imprensa, então no prédio hoje ocupado pelo Cedro esporte Clube, perto do Cinema Olímpia. Aclamações frenéticas: queriam ouvir a palavra de um jornalista em sanção àquele público desagravo à honra do Brasil. (DE CAMPOS, 2005, p. 93).

A inclusão da imprensa ao texto é importante para observar como De Campos Ribeiro entrelaça a realidade à memória, como o uso da notícia na produção do texto. É o que revela (CHIQUIM, 2010, p. 9) quando compara a relação da crônica com o jornalismo. "Nessa transfusão, jornalismo e literatura se misturam, formando , 
um novo tipo sanguíneo: a crônica, um gênero que surgiu junto com o folhetim na imprensa brasileira".

Arnt (2001) explica sobre o termo usado como folhetim e crônica no século XIX:

Esses dois termos são usados indistintamente para designar o que hoje classificamos de crônica. [...]. O termo folhetim designa, também a seção do jornal que vem ao pé da página, separado do corpo das matérias, contendo assuntos diversos, crônicas, folhetins propriamente ditos - isto é, os romances feitos especificamente para serem publicados em capitulos (ARNT, 2001, p. 16-17).

Segundo Arnt (2001) a literatura influenciou diretamente no jornalismo tanto brasileiro como europeu, mas com as devidas proporções, já que no Brasil o atraso na alfabetização da população interferiu negativamente para esse processo. O Fato é que ter escritores trabalhando em redações de jornais já no século XIX iniciou, o que hoje chamamos, de jornalismo literário.

De acordo com Moisés (1978) a crônica só ganhou a atenção dos críticos da literatura depois que começou a ser publicada em livro e dividiu o espaço de divulgação com o jornal. A partir daí, a crônica passou a ser considerada literatura. Mesmo com essa afirmação. Percebe-se na crônica Moral e Cívica, de De Campos Ribeiro, os traços do jornalista diante do cronista quando o autor dá ênfase a dados como endereço e localização espacial:

E tome andar de rua em rua. Largo "Saldanha Marinho", em frente
ao Quartel General, havia retreta. Ululante pedido e concessão ime-
diata da Banda para puxar a passeata, já a essa altura mais pomposa
e dignificada. (DE CAMPOS, 2005, p. 93).

O literato percorre o acontecimento discorrendo pelos detalhes considerados importantes. O fato de a manifestação ter sido noticiada na manhã seguinte, por causa da enorme desordem que causará à cidade. que leva a crer sobre a importância dada por De Campos Ribeiro ao ocorrido. Lembra uma das mais básicas características de notícia, "é um facto actual que tem interesse geral", (CARDET, 1979, p.38).

É o que o autor paraense destaca no trecho

Manhã seguinte, nos jornais o balanço da generalizada desordem que a cidade sofrera. Motorneiro ou condutor de bonde que fosse português inapelavelmente havia sofrido vexames, pancadaria de cego, até com cacetes improvisados das canas pilhadas nas Garapeiras.

A imprensa bradou, veemente, na condenação dos incriveis atentados. (DE CAMPOS, 2005, p. 94).

O humor é uma característica da crônica que a afasta da reportagem propriamente dita. A crônica carrega no seu DNA o indício da reportagem, só a predominância de um elemento literário ou de um outro elemento jornalístico que fará o texto seguir rumo ao jornalismo ou a literatura, Moisés (1978).

No texto Moral e Cívica o humor aparece em vários trechos, mas o fechamento da crônica é o ápice da história vedada ao riso. É quando o autor revela o grande equívoco dos participantes do protesto:

E no final, a revelação, que seria caricata se a isso não se opusessem os estragos, os prejuizos, as vilezas contra pessoas a alheia propriedade: os donos das Garapeiras depredadas eram, quase todos eles, brasileiros! Gente do Ceará, de Pernambuco, daqui mesmo. E, principalmente... gente de Barcarena... (DE CAMPOS, 2005, p. 94).

É neste momento da crônica que o autor aproxima e não deixa fugir a literalidade de suas mãos. Ele utiliza a técnica literária e caminha no estilo literário. Sem falar no hibridismo a que Moisés (1978) se refere: 
A crônica [...] adquire, no livro, uma existência menos falaz: ali se enfeixam as peças que o seu autor julgou resistirem à erosão do tempo, via de regra porque lhes pareceu ostentarem certos méritos, evidentemente não como reportagem, (MOISES, 1978, p. 249).

Moisés (1978) relaciona o local de publicação do texto determinante para alguns críticos em considerar a crônica literatura. No caso dessa abordagem, o texto foi publicado em livro, esse fato leva o texto tender ao seguimento literário se afastando do jornalismo. Por outro lado, quando De Campos relata a história sempre se preocupando em situar o leitor de acordo com o tempo, local, importância do fato para a história e para a sociedade naquele momento vivido, ele influência com sua experiência, jornalisticamente falando, na criação do texto.

O cronista cita ano do provável acontecimento. "Tão séria era a religiosa veneração à Bandeira que certa noite, aí por 1920, resultou em Belém num quebra-quebra danado" (DE CAMPOS, 2005, p. 92). Década de 20, período inicial do movimento moderno nacional e paraense. Fato norteador dos textos de De Campos Ribeiro, quando pensamos nele como militante da Academia do Peixe Frito junto com seus parceiros, homens de ideias desse período.

A Academia do Peixe Frito como instituição que "alimentou" a prática de De Campos Ribeiro é um ponto importante para a observação desta crônica em questão. Foi pensando junto com os parceiros, idealizadores da A.P.F. e frequentadores da feira do Ver-o-Peso que muitas ideias se materializaram em textos literários (Nunes; Costa $>2016$ ), assim como, em crônicas publicadas em jornais e mais tarde em livros do então participante da A.P.F. De Campos Ribeiro.

Segundo os autores (Nunes; Costa: 2016), a A.P.F era uma associação composta por 13 intelectuais que na maioria eram negros, pobres, autodidatas e moradores da periferia de Belém. O que leva a acreditar, que pensamentos vindos desses moços influenciaram nos textos por eles escritos, como exemplo, esta crônica aqui estudada, "Moral e Cívica". Neste texto é observado o pensamento político, cultural e social da época, fatos que circundavam o período Moderno Paraense.

Observa-se o pensamento político quando o literato dá destaque à Bandeira Nacional; o Cultural, quando De Campos ressalta dentro da narrativa os locais em que aconteceu o protesto, como a feira do Ver-o-Peso, o Clube do Remo, o Largo da Sé, dando importância aos pontos que até hoje fazem parte da história antiga e atual da cidade de Belém; do mesmo jeito, De Campos coloca o leitor a pensar sobre os personagens da narrativa, como os estudantes, os atletas e o povo pobre da capital paraense.

Pensando neste viés, chegamos a conclusão de que o autor dá conta do seu papel de cronista e ainda consegue interagir com o leitor como protagonista e observador da história. A crônica "Moral e Cívica" foi lapidada pelo seu autor como um pintor pinta um quadro. Desta maneira, o leitor consegue enxergar Belém através das nuances do texto do literato e ao narrar, De Campos Ribeiro deixa margem de continuidade de uma cidade de Belém como um complexo urbano, Certeau (1994) que Belém se tornara a partir da década de 20, o que foi atestado pela literatura e pelo jornalismo.

\section{REFERÊNCIAS}

ARNT, Héris. A Influência da Literatura no jornalismo: o Folhetim e a Crônica. 126 p. il. Rio de Janeiro: E-papers, 2002.

BLOG ARLS DE CAMPOS RIBEIRO 51. Loja Maçônica. Disponível em: <http://www. dcr51.mvu.com.br/site/historico-/2aN8z8eE-2DE-3/atr.aspx>. Acesso em: 09 jul. 2017.

CARDET, Ricardo. Manual do jornalismo. Tradução Armando Pereira da Silva. Lisboa: Caminho, 1979. 
Petrópolis, Vozes, 1994.

CHIQUIM, Giovana. Quando a notícia vira fato literário: as crônicas de Drummond inspiradas no jornalismo. 153 f. Dissertação (Mestrado em Letras) - Universidade Estadual de Londrina, Londrina, 2010.

DE CAMPOS, Ribeiro. Gostosa Belém de Outrora. 2 ed., Belém: SECULT-PA, 2005.

HALBWACHS, Maurice. A Memória Coletiva. Trad.: Beatriz Sideau. São Paulo, Centauro, 2006.

LEAL, Luiz Augusto Pinheiro. Gladiadores de escassa musculatura: sociabilidade, literatura e responsabilidade intelectual na Amazônia. Belém: IAP, 2014.

MOISÉS, Massaud. A Criação Literária: Prosa. São Paulo: Cultrix, 1978.

MOTTA, Luis Gonzaga. Análise Crítica da narrativa. Brasília: Editora Universidade de Brasília, 2013.

MENDES, Larissa de Morais Ribeiro. Outras práticas, outra narrativas: jornalismo em transformação nos blogs de notícias. Dissertação (Mestrado em Comunicação Social), Pontifícia Universidade Católica do Rio de Janeiro (PUC-Rio), fev. 2007.

NUNES, Paulo e COSTA, Vânia Maria Torres. Academia do Peixe Frito: diálogos e intersecções entre Literatura, jornalismo e Ciências Sociais na Amazônia do século XX. Artigo apresentado $40^{\circ}$ Encontro Anual da Anpocs. ST02. Belém: 2016.

SANT’ANNA, Sérgio. Contos e novelas reunidas. São Paulo: Companhia das Letras, 1997.

SODRÉ, Nelson Werneck. A história da imprensa no Brasil. Rio de Janeiro: Mauad, 1999.

TÓFOLI, Luciene. Ética no jornalismo. Petrópolis,RJ: Vozes, 2008. cação Social - Habilitação em Jornalismo pela Universidade da Amazônia (2016). E-mail: alcione.carepa@hotmail.com

Doutor em Letras - Literaturas em Língua Portuguesa - pela Pontifícia Universidade Católica de Minas Gerais. É professor titular da Universidade da Amazônia, onde atua na graduação em Letras, mestrado e doutorado em Comunicação, Linguagens e Cultura da UNAMA. É um dos coordenadores do Grupo de Estudos interinstitucionais (UNAMA/UFPA) Narramazônia: narrativas contemporâneas da Amazônia Paraense, e um dos coordenadores do projeto de Pesquisa Academia do Peixe Frito: interfaces jornalismo e literatura. E-mail: pontedogalo3@gmail.com 